\title{
Rhesus macaques vaccinated with consensus envelopes elicit partially protective immune responses against SHIV SF162p4 challenge
}

\author{
Hermancia S Eugene ${ }^{1,3}$, Brooke R Pierce-Paul ${ }^{1}$, Jodi K Craigo ${ }^{1,2,3}$ and Ted M Ross ${ }^{1,2,3^{*}}$
}

\begin{abstract}
The development of a preventative HIV/AIDS vaccine is challenging due to the diversity of viral genome sequences, especially in the viral envelope $\left(E n v_{160}\right)$. Since it is not possible to directly match the vaccine strain to the vast number of circulating HIV-1 strains, it is necessary to develop an HIV-1 vaccine that can protect against a heterologous viral challenge. Previous studies from our group demonstrated that a mixture of wild type clade B Env $_{\mathrm{gp} 160 \text { s }}$ were able to protect against a heterologous clade B challenge more effectively than a consensus clade B Env $_{\mathrm{gp} 160}$ vaccine. In order to broaden the immune response to other clades of HIV, in this study rhesus macaques were vaccinated with a polyvalent mixture of purified HIV-1 trimerized consensus Env $v_{\text {gp } 140}$ proteins representing clades A, B, C, and E. The elicited immune responses were compared to a single consensus Env ${ }_{\text {gp } 140}$ representing all isolates in group $\mathrm{M}$ (Con M). Both vaccines elicited anti- Env $\mathrm{gp}_{140} \mathrm{lg} \mathrm{G}$ antibodies that bound an equal number of HIV-1 Env ${ }_{\text {gp160 }}$ proteins representing clades A, B and C. In addition, both vaccines elicited antibodies that neutralized the HIV-1 ${ }_{\text {SF162 }}$ isolate. However, the vaccinated monkeys were not protected against SHIV $V_{\text {SF162p4 }}$ challenge. These results indicate that consensus Env $_{\mathrm{gp} 160}$ vaccines, administered as purified Env $_{\mathrm{gp} 140}$ trimers, elicit antibodies that bind to $E_{n v_{\text {gp } 160 s}}$ from strains representing multiple clades of HIV-1, but these vaccines did not protect against heterologous SHIV challenge.
\end{abstract}

\section{Introduction}

One of the greatest struggles for developing a preventative human immunodeficiency virus (HIV)/acquired immunodeficiency syndrome (AIDS) vaccine is overcoming the diversity of viral isolates [1]. The $\operatorname{Env}_{\mathrm{gp} 160}$ sequences can differ up to $35 \%$ between clades and $\sim 15 \%$ within a specific clade [2]. Viruses classified as clade B are responsible for $\geq 40 \%$ of infections in the Americas and Europe, but in Asia and sub-Saharan Africa, where most new infections are recorded each year, other clades are dominant. Most new infections in these regions are classified as clades $\mathrm{A}$, $\mathrm{C}$, or $\mathrm{A} / \mathrm{E}$ viruses $[1,3]$. Any HIV vaccine that will prevent infection must be able to overcome the diversity of HIV sequences.

\footnotetext{
*Correspondence: tmr15@pitt.edu

${ }^{1}$ Center for Vaccine Research, University of Pittsburgh, 9047 BST3; 3501 Fifth

Avenue, Pittsburgh, PA 15261, USA

${ }^{2}$ Department of Microbiology and Molecular Genetics, University of

Pittsburgh, Pittsburgh, PA, USA

Full list of author information is available at the end of the article
}

To overcome the HIV sequence diversity, polyvalent mixture of antigens and consensus proteins were designed [4-7]. Polyvalent vaccines increase breadth by including multiple copies of a target (s) or epitopes into a single formulation. Polyvalent vaccine strategies have been employed to increase the breadth of the humoral and cellular immune responses [8,9]. Polyvalent mixtures of $\operatorname{Env}_{\mathrm{gp} 140}$ or HIV proteins (Gag-Pol, Tat and trimeric $\mathrm{Env}_{\mathrm{gp} 140}$ ) elicit a degree of protection against heterologous challenge $[8,10]$. Consensus-based vaccines rely on a centralized antigen designed to reduce sequence diversity by using the most common amino acid at each position of the protein. Consensus vaccines are designed to reduce the genetic differences between the vaccine and the primary isolate and increase the breadth of immune responses [11-14].

To overcome the diversity in $\mathrm{Env}_{\mathrm{gp} 160}$ sequences and to design a more effective AIDS vaccine, consensus Env $_{\text {gp140 }}$ sequences were designed for 4 clades of HIV-1 (A, B, C, and $\mathrm{E})$, as well as a single consensus Env $\mathrm{gp}_{\mathrm{g} 160}$ representing isolates from all of Group M. For the first time, in the

\section{Biomed Central}


same study, consensus A, B, C, and E Env gp140 $_{\text {sequences }}$ were used in a polyvalent vaccine mixture, and compared to a Con M Env $\mathrm{gp}_{160}$, to assess the ability to elicit a broadly reactive anti-Env ${ }_{\mathrm{gp} 160}$ immune response. The immunological responses of the polyvalent mixture in vaccinated rhesus macaques were compared to that of the single Con $\mathrm{M} \mathrm{Env}_{\mathrm{gp} 140}$ vaccine. Both vaccines elicited anti-Env immune responses against multiple clades of HIV; however neither vaccine strategy efficiently protected monkeys against a SHIV $\mathrm{SF162p}_{4}$ challenge.

\section{Results}

\section{Characterization of consensus envelopes}

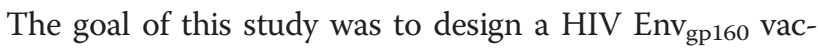
cine that elicits broadly reactive immune responses in an effort to overcome the inherent diversity in the Env ${ }_{\mathrm{gp} 160}$.

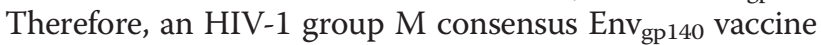
was compared to a polyvalent mixture of clade consensus
Env $_{\text {gp140s }}$ representing 4 individual clades of HIV-1 (A, B, $\mathrm{C}$, and $\mathrm{E}$ ). The env gene sequences were then truncated at the transmembrane domain, and the cleavage site mutated, to generate a $\operatorname{Env}_{\mathrm{gp} 140}$ [15]. To stabilize the truncated Env $_{\text {gp140 }}$ trimers, the bacteriophage fibronectin domain (FT) was added to the 3' end of the Env ${ }_{\text {gp140 }}$ sequence, as previously described [15].

Purified trimerized Envs were detected at $\sim 480 \mathrm{kDa}$ size indicating oligomerization as trimer proteins (Figure 1A). Some Env dimers were observed in consensus C, E and M Env $_{\text {gp140 }}$ protein fractions. To probe the antigenic structure, the broadly reactive monoclonal antibody b12 [16] was used to determine binding kinetics to each consensus envelope by surface plasmon resonance (SPR) on a Biacore 3000 (Figure 1B and Additional file 1: Figure S1). The rate of association between the consensus Env $_{\text {gp } 140}$ trimers and b12 was similar to the rate of association between b12 and primary $\mathrm{Env}_{\mathrm{gp} 140}$ trimers. The rate of dissociation of b12

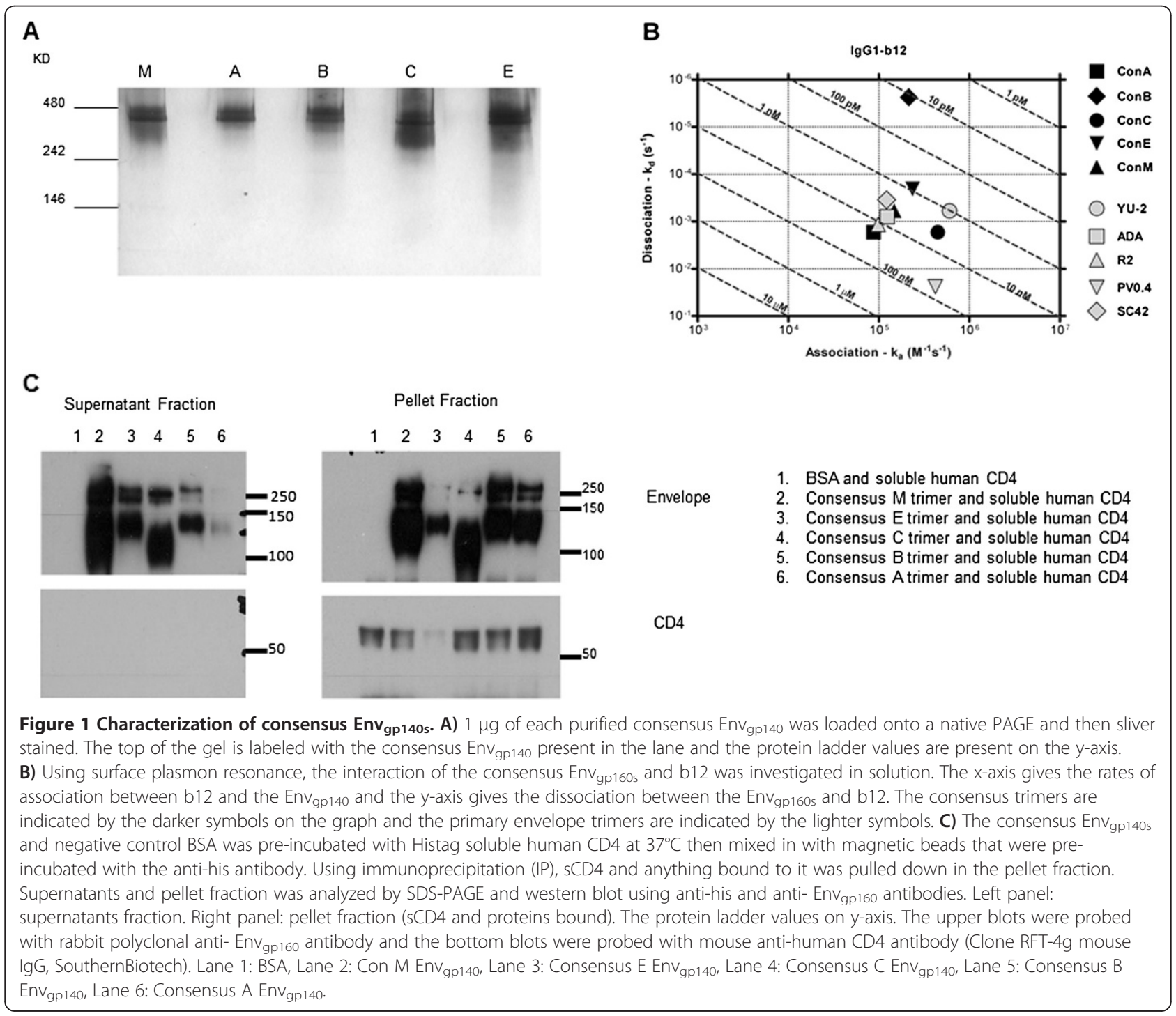


from all the $E v_{g p 140}$ trimers was similar, except for consensus B, which had a slower rate of disassociation. Each Env $_{\mathrm{gp} 140}$ bound to the primary HIV receptor, human CD4 (hCD4) (Figure 1C). The MAb b12 is a monoclonal isolated from an infected patient with a consensus B wild-type Env $_{\mathrm{gp} 160}$ on its viral surfaces and therefore may recognize clade B Env ${ }_{\mathrm{gp} 160}$ with more efficiency than non-clade B $E_{\text {gn } 160 s}$. In addition, consensus $B$ envelopes are bound with higher affinity antibodies to clade B $\mathrm{Env}_{\mathrm{gp} 160 \mathrm{~s}}$, but less so with consensus $C$ Env $_{\mathrm{gp} 140}$. The reverse is true as well. A polyclonal serum, HIV-Ig, was obtained from the AIDS Reference and Reagent Program. This polyclonal serum, collected from a clade B infected person, may not recognize the consensus $E E v_{\mathrm{gp} 160}$ with the same affinity and efficiency as the consensus B Env gp160. $_{\text {. }}$.

\section{Vaccination of non-human primates with consensus envelopes}

To determine the ability of the vaccines to induce a protective response in non-human primates, rhesus macaques were vaccinated intramuscularly with $300 \mu \mathrm{g}$ of total $\mathrm{Env}_{\mathrm{gp} 140}$ protein either Con $\mathrm{M}$ or the polyvalent Con Mixture (equal amounts of each Env $_{\mathrm{gp} 140}$ protein). Animals were treated according to the guidelines of the IACUC of the University of Pittsburgh. All the protocols used were approved by the IACUC of the University of Pittsburgh (\#1002617). Monkeys were administered 3 vaccinations of $\mathrm{Env}_{\mathrm{gp} 140}$ formulated with Imject $^{\circledR}$ alum adjuvant. Mock vaccinated monkeys were administered PBS formulated with adjuvant (Table 1). Monkeys vaccinated with Con $\mathrm{M}$ or polyvalent consensus developed anti$\mathrm{Env}_{\mathrm{gp} 140}$ antibody titers greater than 1:400 dilution against all consensus $E_{n v_{g p 160 s}}$ following the three vaccinations (Figure 2A). Collected sera were tested for the ability to bind to a set of primary Env $_{\mathrm{gp} 160 \mathrm{~s}}$ representing clades A, B, $\mathrm{C}$, and $\mathrm{E}$ (Table 2). The diversity of the $\mathrm{Env}_{\mathrm{gp} 160 \mathrm{~s}}$ chosen, as well as their similarity to the consensus Envgp160s, is displayed in the phylogenetic tree where $\mathrm{Env}_{\mathrm{gp} 160 \mathrm{~s}}$ cluster into their identified clades (Figure 2B). The Con $\mathrm{M}$ did not cluster with any one clade, but as expected, was located in a more central position on the tree.

Both Con $\mathrm{M}$ and polyvalent consensus $\mathrm{Env}_{\mathrm{gp} 140}$ vaccines elicited anti- $\operatorname{Env}_{\mathrm{gp} 140}$ antibodies that recognized $\mathrm{Env}_{\mathrm{gp} 160 \mathrm{~s}}$ from clade A, B and C. However, the $\mathrm{Env}_{\mathrm{gp} 160}$ SC42, THRO4, PVO4, (clade B), DU172 (clade C) and
93TH975 (clade E) were not significantly recognized by sera collected from vaccinated animals (Figure 2C). Overall, there was no binding preference of the elicited anti-Env $v_{\mathrm{gp} 160}$ antibodies to primary Env $v_{\mathrm{gp} 160 \mathrm{~s}}$ based on clade, location, or year of $\mathrm{Env}_{\mathrm{gp} 160}$ isolation.

\section{SHIV $_{\text {SF } 162 \mathrm{p} 4}$ challenge}

To evaluate the protective efficacy of each vaccine, monkeys were challenged rectally four weeks after final vaccination with SHIV SF162p4 $_{\text {(dose: }} 640_{\mathrm{TCID} 50}$ ) to ensure all mock vaccinated animals become infected. All mock vaccinated and polyvalent consensus vaccinated monkeys were infected following challenge (Figure $3 \mathrm{~A}$ and $\mathrm{B}$ ). Viral loads peaked at day 14 post-challenge at $\sim 1 \times 10 \mathrm{e}+6 \mathrm{RNA}$ copies $/ \mathrm{ml}$ and then declined to undetectable levels by day 80 post-infection as seen in previous studies using the same stock of virus (unpublished and [8]. Two out of four monkeys (M1 and M4) vaccinated with Con M vaccine had no detectable virus at any time point post-challenge (Figure 3C). Monkeys M2 and M3 had a similar viral pattern as mock vaccinated monkeys with a peak at day 14, followed by a rapid decline.

To determine whether Con $M E n_{g p 140}$ vaccinated monkeys were protected from infection, at day 70 postchallenge all Con $\mathrm{M} \mathrm{Env}_{\mathrm{gp} 140}$ vaccinated monkeys were depleted of CD8+ cells by administering monoclonal antibody M-T807R1 intravenously [17]. Seven days following antibody administration, no CD8+ cells were detected in the peripheral blood that was sustained for an additional 18 days (Figure 4A). Previously infected monkeys M2 and M3 had a re-emergence of virus during this CD8+-depletion period (Figure 4B). Monkey M4 who was initially aviremic after challenge had an emergence of virus after CD8+-depletion. In contrast, monkey M1 maintained undetectable viral loads following CD8+ depletion.

\section{Responses to the challenge envelope SF162}

At 2 weeks after final vaccination (day -14 prior to challenge), anti-Env ${ }_{\mathrm{SF} 162}$ IgG antibodies were detected in monkeys vaccinated with either vaccine (Figure $2 \mathrm{C}$ ). In addition, these antibodies were able to neutralize the ability of $\mathrm{HIV}_{\mathrm{SF} 162}$ to infect cells in vitro (Figure 5A). The presence of neutralization titers to all $\mathrm{Env}_{\mathrm{gp} 160 \mathrm{~s}}$ used in the ELISA binding assay were investigated, however,

Table 1 Vaccine groups and regimen of non-human primate study

\begin{tabular}{llll}
\hline Vaccine group & Animal numbers & Vaccine given & Other treatment \\
\hline Group 1 & $\mathrm{~N} 1, \mathrm{~N} 2, \mathrm{~N} 3, \mathrm{N4}$ & Adjuvant only & \\
Group 2 & $\mathrm{P} 1, \mathrm{P} 2, \mathrm{P} 3, \mathrm{P} 4$ & Mixture of Con A,B,C,E Env gp140 & Depletion of CD8+ T cells \\
Group 3 & $\mathrm{M} 1, \mathrm{M} 2, \mathrm{M} 3, \mathrm{M} 4$ & Con M Env gp140 &
\end{tabular}

Each animal was vaccinated 3 times week 0,4 and 8 . Each vaccine was given in combination alum imject $\odot$ as an adjuvant. The table gives the vaccine groups, the identification number of animals in each group and the vaccine and treatment (in the case of group 3 ) received by the animals. 


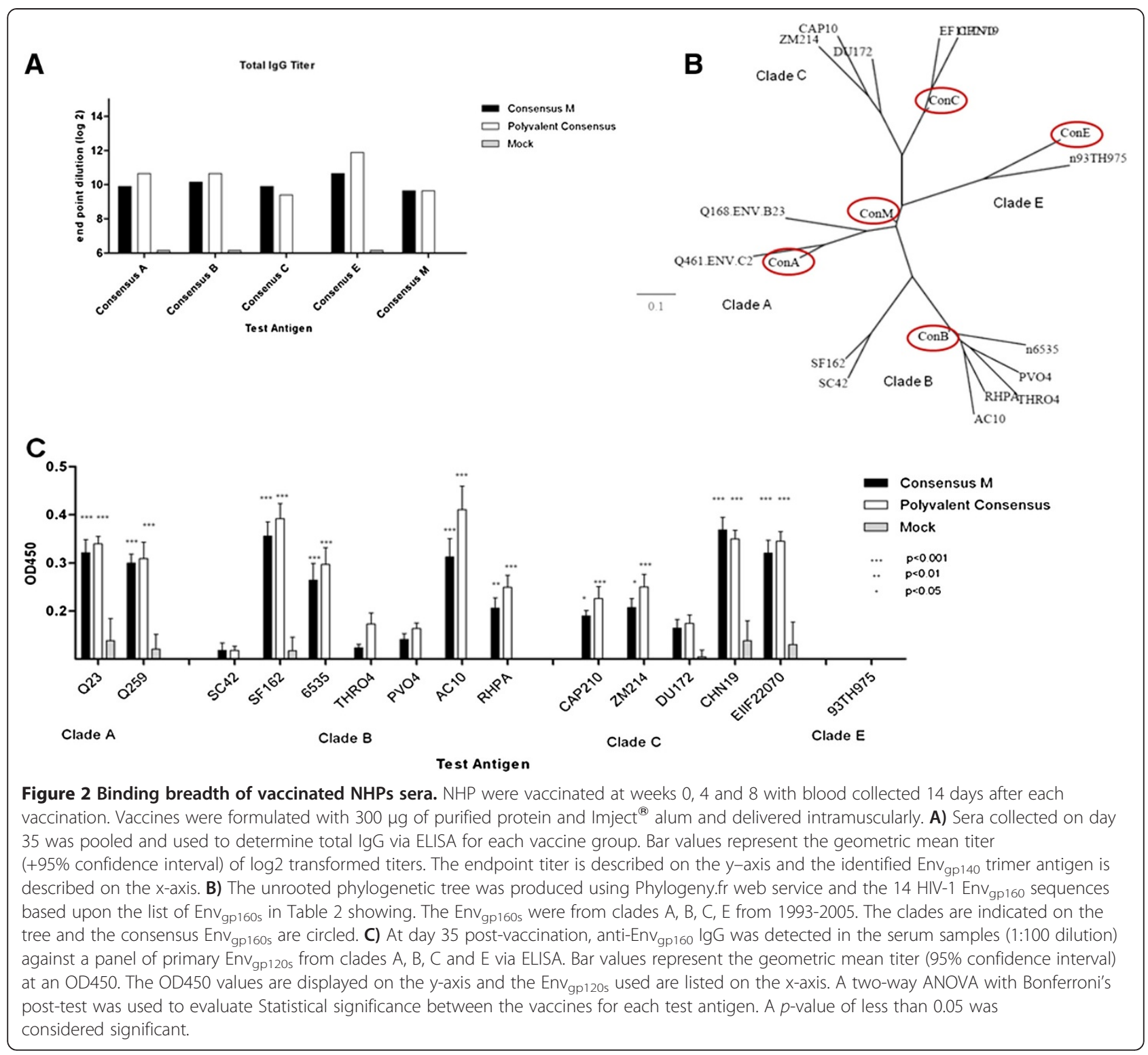

only titers to HIV $\mathrm{SF}_{\mathrm{SF} 2} \mathrm{Env}_{\mathrm{gp} 160}$ was observed. All vaccinated monkeys had a neutralizing titer of 1:40, except for monkey M4 that had a titer of 1:320. Two weeks following challenge, only monkey $\mathrm{P} 4 \mathrm{had}$ an increase in neutralizing titers. There were detectable neutralization titers in 3 of the 4 mock vaccinated monkeys two weeks post-challenge (Figure 5A). No monkey had antibodies that recognized a set of overlapping SF162 Env ${ }_{g p 160}$ peptides. These pools of peptides represented the SF162 Env $_{\text {gp160 }}$ regions V1/V2, V1 only, or V2 only (data not shown). Interestingly, there was no detectable IFN- $\gamma$ Env $_{\text {gp160 }}$ or gag-specific T-cell responses prior to challenge or 7 days post-challenge. At day 14 and 21 postchallenge, IFN- $\gamma \mathrm{T}$ cell responses were detected in all monkeys (Figure 5B), with no significant differences in the number of cells between groups.

\section{Discussion}

HIV-1 Env gp 160 based vaccines protect monkeys against a homologous SHIV challenges $[18,19]$. The ability to match the gene sequences used in the vaccine to the possible exposure virus in humans is not possible. Therefore, studies that use a matched $E_{\text {gnv }} v_{60}$ in the vaccine to the challenge strain is appropriate for proof-of concept studies, but our group set a more challenging goal to protect against a challenge virus with a mismatched vaccine with a limited number of vaccinations. We report here that each consensus sequence representing clade A, B, C, E, in a polyvalent mixture or as a single consensus $\mathrm{Env}_{\mathrm{gp} 160}$ representing the entire Group $M$ elicited anti-Env $v_{\mathrm{gp} 140}$ antibodies that bound to a broad panel of HIV-1 $\mathrm{Env}_{\mathrm{gp} 160} \mathrm{~S}$. The immunization schedule used was not optimal for antibody affinity maturation; nonetheless, the 
Table 2 Information of envelopes used for assays

\begin{tabular}{|c|c|c|c|c|c|c|}
\hline Env ID & Clade & Location & Mode of transmission & Length of infection & Mo/yr isolated & Corecepter \\
\hline Du172.17 & C & South Africa & $M-F$ & 12 weeks & Nov-98 & R5 \\
\hline ZM214M.PL15 & C & Zambia & $\mathrm{F}-\mathrm{M}$ & $<13$ weeks & Jul-03 & R5 \\
\hline CAP210.2.00.E8 & C & South Africa & $M-F$ & 5 weeks & May-05 & R5 \\
\hline CHN19 & C & China & & & & R5 \\
\hline HIV16936-2 EF117270 & C & India & $\mathrm{F}-\mathrm{M}$ & 1 week & Nov-00 & R5 \\
\hline Q168.ENV.B23 & $A$ & Kenya & $M-F$ & 1 week & & R5 \\
\hline Q461.ENV.C2 & A & Kenya & $M-F$ & 4 weeks & & R5 \\
\hline HIV env 6235 clone 3 & B & USA & M-M & 6 weeks & Mar-95 & R5 \\
\hline PVO clone 4 & B & Italy & $M-M$ & 4 weeks & Jan-96 & R5 \\
\hline pRHPA 4259 clone7 & B & USA & $M-F$ & $<$ weeks & Dec-00 & R5 \\
\hline pTHRO4156 clone 18 & B & USA & $M-M$ & 1 week & Aug-00 & R5 \\
\hline SC 422661.8 & B & Trinidad & F-M & 4 weeks & Jan-95 & R5 \\
\hline SF162 & B & USA & & & & R5 \\
\hline 93ТН975-15 & E & Haiti & $F-M$ & $<18$ weeks & Jan-93 & R5 \\
\hline
\end{tabular}

Primary envelopes from various clade was chosen based to have a diversity of locations and mode of mocusal transmission. Envelopes were used to test the presence of binding and neutralizing antibodies elicited by vaccination of consensus vaccines in non-human primates. SF162 was included because it is the challenge virus envelope.

regimen did induce modest neutralizing antibody titers to the challenge $\mathrm{Env}_{\mathrm{gp} 160}$. However, the elicited immunity did not prevent infection by SHIV $_{\text {SF162p } 4 \text {. }}$

In previous studies, consensus sequences designed for clades B and C Gag and $\mathrm{Env}_{\mathrm{gp} 140}$ elicited increased breadth of humoral and cellular immune responses [12,20-22]. Consensus $\mathrm{Env}_{\mathrm{gp} 160}$ sequences representing Group $\mathrm{M}$, termed CON-S, elicited antibodies that neutralized multiple Env $_{\mathrm{gp} 160 \mathrm{~s}}$, as well as eliciting crossclade cellular immune responses [13,14]. However, viral challenges of CON-S vaccinated monkeys were not reported and therefore the efficacy of the induced immune response elicited by these vaccines is unknown.

Compared to $\mathrm{Env}_{\mathrm{gp} 120}$ monomers, $\mathrm{Env}_{\mathrm{gp} 140}$ trimers may expose binding and neutralizing epitopes that are present only in Env's quaternary state [23,24]. Our consensus $\mathrm{Env}_{\mathrm{gp} 140}$ trimers have similar antigenic properties as wild-type $\mathrm{Env}_{\mathrm{gp} 160 \mathrm{~s}}$, as demonstrated by attaching to human CD4 and binding to the monoclonal antibody b12. The b12 antibody recognizes a conserved region on gp120 mapped to a discontinuous epitope overlapping the CD4 binding site [25].

Following three intramuscular vaccinations, all monkeys seroconverted by day 14 following the final vaccination. Nonetheless, there were differences in the vaccine efficacy following challenge between the two vaccine groups. Both non-neutralizing and neutralizing antibodies have been implicated in reducing rates of infection by HIV-1 [26,27]. A report based on the analysis of the sera samples of vaccinated volunteers in the RV144 clinical trial stated that the vaccine elicited antibodies against the $\mathrm{V} 2$ region of the HIV-1 Env gp160 $_{\text {were }}$ correlated with lower rates of HIV infection [28]. Antisera collected from these vaccinated individuals did not neutralize the infection in vitro. Additionally, vaccine induced protection against a neutralization resistant virus in macaques was correlated with antibodies to the V2 region of $\operatorname{Env}_{\mathrm{gp} 160}$ [29]. Whether antibodies that bind to the $\mathrm{V} 2$ region are correlated with protection against SHIV $_{\text {SF162p } 4}$ infection in this study is unclear. There were no antibodies elicited in monkeys vaccinated with Con $\mathrm{M}$ or polyvalent consensus $\mathrm{Env}_{\mathrm{gp} 140}$ vaccines that recognized SF162 $\mathrm{Env}_{\mathrm{gp} 160}$ linear peptides, including those specific to V2 (data not shown). Further studies are necessary to determine if the two protected animals in the Con $M$ Env $_{\mathrm{gp} 140}$ group elicited antibodies recognizing conformational epitopes, such as the V1/V2 scaffold proteins. The V1/V2 scaffold was used to analyze human sera collected from vaccinated volunteers in the RV144 clinical trial [30,31]. Determining if antibodies specific to various conformational epitopes on $\mathrm{Env}_{\mathrm{gp} 160}$ may explain the differences observed in vaccinated animals following SHIV challenge.

Two monkeys that had no detectable viral levels following SHIV infection were M1 and M4. M2 and M3 had detectable viral levels and therefore were not protected against infection. Monkeys vaccinated with either polyvalent consensus or Con $\mathrm{M} \mathrm{Env} \mathrm{gp}_{\mathrm{gp}}$ trimers had neutralizing titers to HIV-1 $1_{\mathrm{SF} 162}$. Neutralizing antibodies against $\mathrm{Env}_{\mathrm{gp} 160}$ can protect monkeys against viral challenge $[32,33]$. However, only one monkey (M4) in the present study had high neutralizing antibodies (1:320) against SHIV $_{\text {SF162p4 }}$ and had undetectable viral titer 14 days after challenge. However, following CD8+ T cell depletion, virus was detected $\left(<1 \times 10^{5}\right.$ RNA copies $\left./ \mathrm{ml}\right)$ in the blood indicating that infection was not blocked, but may have been 


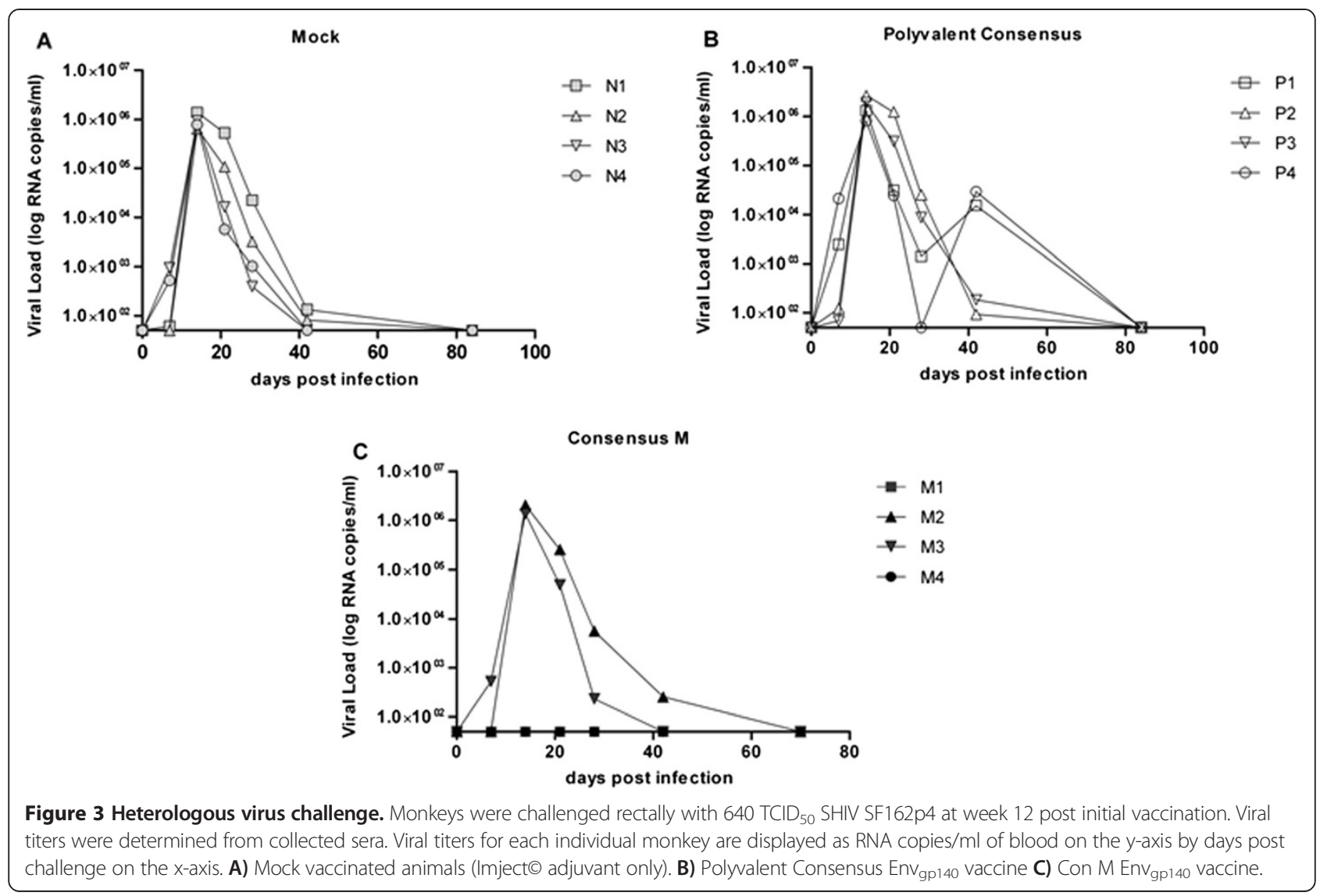

controlled by the vaccine elicited antibodies. $\mathrm{T}$ cell responses did not appear to play a role in protecting the monkeys from infection. There was no difference in the number or kinetics in the elicitation of $E_{n v_{g p 160}}$ or Gag specific IFN $\gamma$ producing cells following challenge in any of the vaccinated monkeys compared to mock vaccinated animals.

Upon CD8+ depletion, it was not unexpected that M2 and M3 had a rebound in blood titer virus, but the detection M4 was unexpected. In contrast to monkey M4, no virus was detected in monkey M1 even after depletion of CD8+ T cells. Both IFNy specific T cells and neutralizing antibodies were detected, but it is unclear which of these immune responses may have contributed to the protection. In addition, the MHC class I haplotype did not appear to correlate with protection. Even though no viremia was ever detected in monkey M1, it is possible that virus could be located in reservoirs, such as the bone marrow or gut mucosa [34]. The M-T807R1 monoclonal antibody used for CD8+ T cell depletion is specific for cells in the serum and lymph nodes [35], therefore, it may have not depleted cells in reservoirs of hidden virus. In an effort to identify possible reasons for M1 protection the animals' halotypes were determined. Monkey M1 had a Mamu-B *008 MHC class I haplotype, which has been associated with control of $\operatorname{SIV}_{\text {mac239 }}$ virus; the parent virus of the challenge SHIV ${ }_{\text {SF162p4 }}$ [36]. Therefore, a combination of the neutralizing antibodies, non-neutralizing antibodies and the Mamu-B*008 MHC class I haplotype may have resulted in "sterilizing" protection after viral challenge. However, the Mamu-B*008 MHC class I haplotype was also present in monkey M3, which had similar binding and neutralizing antibody titers as monkey M1, but was not protected from SHIV infection. Interestingly, two monkeys vaccinated with the polyvalent consensus vaccine, P2 and $\mathrm{P} 4$, had a rebound in viral titers at day 40 post-infection before returning to undetectable levels (Figure 3B). The rebound virus could have been a variant that escaped the vaccine elicited immune response, however, sequencing of the virus in the blood collected at day 40, did not show any significant variation of the viral sequence compared to the input virus on day 0 .

While Env gp140 $_{1}$ only vaccines have been successful against homologous challenge, both the human RV144 trial and previous monkey studies showed significant protection from heterologous challenge, included other HIV protein components $[8,37,38]$. Including Tat in the vaccine formulation induces strong and persistent $\mathrm{CD}_{4}^{+} \mathrm{T}$ cells [39] and broadens $\mathrm{T}$ cell responses directed against Gag and $\mathrm{Env}_{\mathrm{gp} 160}[40,41]$. Gag is known for inducing strong cellular responses that may lead to reduced viral loads 


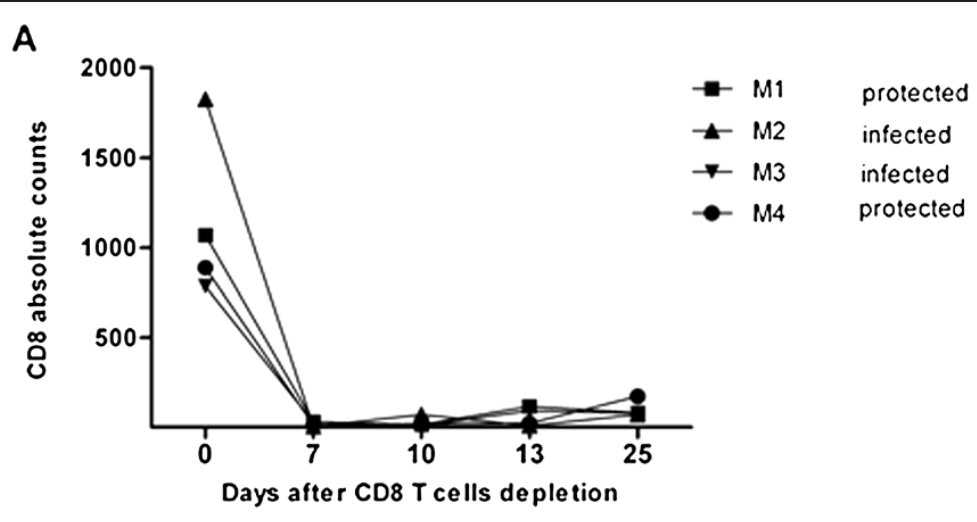

B

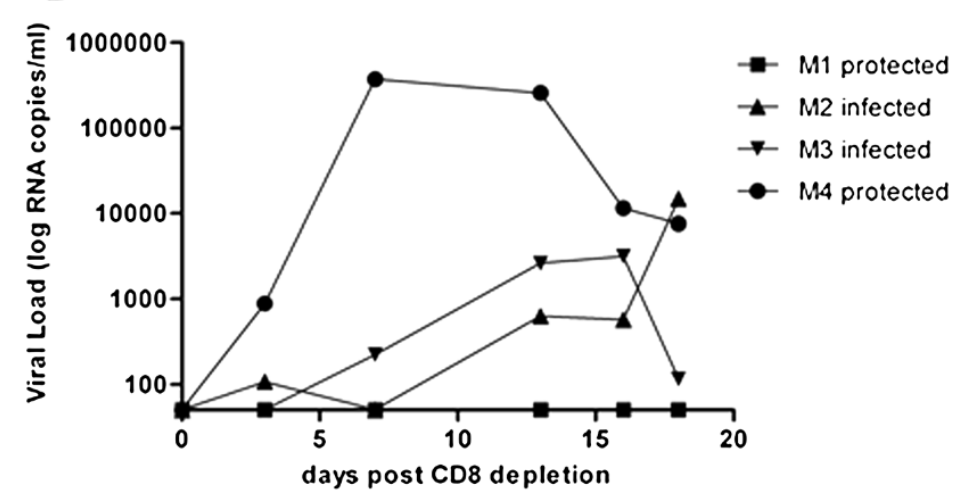

Figure 4 CD8+ T cell depletion. Animals vaccinated with Con M Env ${ }_{g p} 140$ were all depleted of CD8+ cells by administering the M-T807R1 antibody subcutaneously (50 mg/Kg) at day 0 (day 70 post challenge). A) Number of CD8+ cells following antibody administration over the 25 day period of observation. B) Viral titers for each individual monkey are displayed as RNA copies/ml of blood on the $y$-axis by days post challenge on the $x$-axis.

$[42,43]$. Addition of Gag and/or Tat to our Con M vaccine may have prevented infection or controlled undetectable virus in vaccinated animals more effectively than Con $M$ Env $_{\mathrm{gp} 140}$ alone. Even though some of these studies use Env $_{\mathrm{gp} 140}$ proteins, they are combined with other HIV proteins to elicit a broadly reactive response. In our vaccine presented here, the purified VLPs only have Gag and Env $_{\mathrm{gp} 140}$ expressed in different modalities than VLPs and we achieve a broadly reactive anti-Env ${ }_{g p 140}$ response using our consensus $E_{\mathrm{gp} 160 \mathrm{~s}}$. For example, viral vectors are used to express Gag and $\mathrm{Env}_{\mathrm{gp} 160}$ independently in the RV144 human trial, which really does not allow for comparison with our VLP strategy.

\section{Conclusion}

Rhesus macaques were vaccinated with trimerized $\mathrm{Env}_{\mathrm{gp} 140}$ proteins representing consensus sequences for clade $\mathrm{A}, \mathrm{B}$, $\mathrm{C}, \mathrm{E}$, in a polyvalent mixture or as a single consensus Env $_{\mathrm{gp} 160}$ representing the entire Group M. These consensus $E_{\mathrm{gp} 140}$ elicited antibodies with cross-clade anti-Env

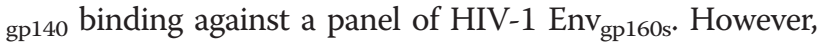
this breadth of antibody binding to HIV-1 $\mathrm{Env}_{\mathrm{gp} 160 \mathrm{~s}}$ only partially correlated with the prevention of infection by SHIV ${ }_{\text {SF162p } 4}$.

\section{Materials and methods \\ Vaccines design}

The consensus sequences represent the most common amino acids found at each position of the aligned envelope sequences used. One hundred $\operatorname{Env}_{\mathrm{gp} 160 \mathrm{~s}}$ sequences per clade were used to design consensus sequences of clades $\mathrm{A}, \mathrm{B}, \mathrm{C}$, and $\mathrm{E}$. The design of the group $\mathrm{M}$ consensus $\mathrm{Env}_{\mathrm{gp} 160}$ was based on two hundred $\mathrm{Env}_{\mathrm{gp} 160}$ sequences representing clades A, B, C, D, E, F and H. Env ${ }_{\mathrm{gp} 160 \mathrm{~s}}$ chosen were isolated following mucosal transmission, within weeks after infection and included a diversity of viruses that were isolated in different locations around the world between 1995 and 2005. Each Env ${ }_{\text {gp160 }}$ used the CCR5 co-receptor. Vaccine immunogens were designed as Env $_{\mathrm{gp} 140}$ trimers as previously described [15].

\section{Protein purification}

Human embryonic kidney (HEK) 293T cells were transiently transfected with DNA $(8 \mu \mathrm{g})$ expressing one of the consensus HIV-1 Env ${ }_{\mathrm{gp} 140}$ proteins or wild type $\mathrm{Env}_{\mathrm{gp} 120}$ 


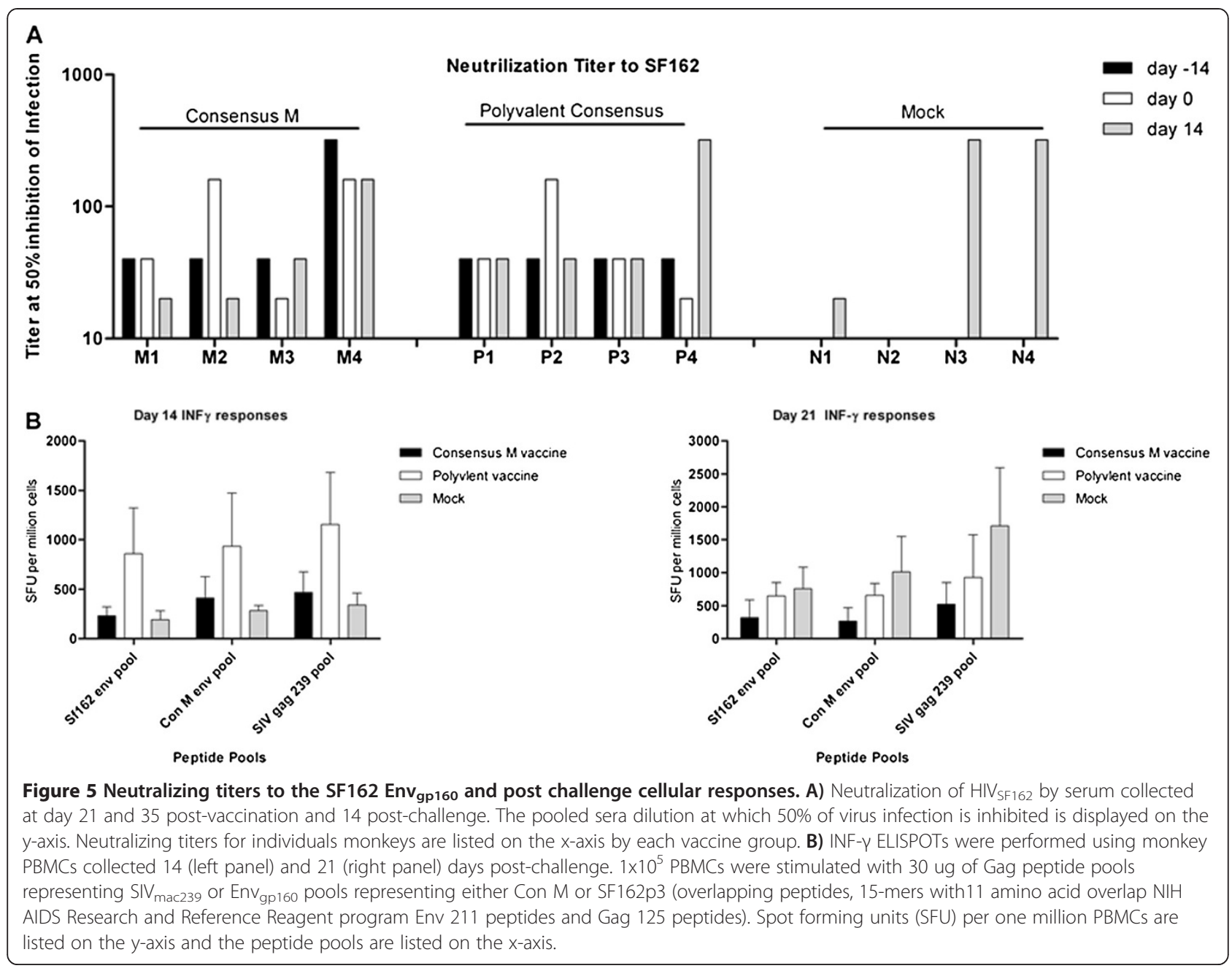

6X-HIS tagged proteins. Following DNA transfection as previously described [44], secreted Env $_{\text {gp140 }}$ proteins were purified using lectin columns made from agarose galanthus nivalis (snowdrop) lectin (Vector laboratories, Burlingame, CA, USA) [45] and the Env $_{\text {gp } 120} 6 \mathrm{X}$-HIS tagged proteins were purified using nickel columns [44]. Other purified Env $_{\text {gp } 160 s}$ used for ELISAs were purchased from eEnzyme (Gaithersburg, MD, USA). Each purified consensus Env gp140 trimer protein $(1 \mu \mathrm{g})$ was loaded on to NativePAGE native gel (Invitrogen, Carlsbad, CA, USA) and separated by electrophoresis in the manufacture's recommended buffers. After separation, the proteins were detected using the ProteoSilver Sliver Stain kit (Sigma, St. Louis, MO, USA) following manufacturer's protocol [44].

\section{CD4 binding assay}

The CD4 binding assay was performed to demonstrate Env $_{\text {gp160 }}$ binding to its primary receptor using a similar protocol as previously described [46]. Protein G Dynabeads (Invitrogen) were mixed with anti-his antibody. The tubes with the mixture were placed on the magnets to remove all unbound antibody. Then soluble human CD4-6XHIS tagged protein (eEnzyme, Gaithersburg, MD, USA) and consensus $E_{\text {gnv } 140}$ mixtures were then mixed with the beads. Following pellet fractionation, samples were separated on a $10 \%$ SDS PAGE gel, transferred unto a nitrocellulose membrane and probed for sCD4 or $\mathrm{Env}_{\mathrm{gp} 160}$ using specific antibodies. Following secondary IgG-HRP antibodies which were used to detect proteins by Western blot.

\section{Surface plasmon resonance}

MAb b12 binding kinetic analyses of the HIV rgp140(s) was performed by surface plasmon resonance (SPR) on a Biacore 3000 (GE/Biacore AB, Inc., Uppsala, Sweden) as previously described [47].

\section{Animals and vaccination}

Animals were treated according to the guidelines of the IACUC of the University of Pittsburgh. All the protocols used were approved by the IACUC of the University of Pittsburgh (\#1002617). Rhesus macaques (Macaca mulatta) were used for all non-human primate 
experiments. All animals were cared for adhering to USDA guidelines for laboratory animals. Rhesus macaques were anesthetized using 10-20 mg/kg ketamine and vaccinated intramuscularly in the quadriceps and formulated with Imject ${ }^{\circledR}$ alum adjuvant (Imject ${ }^{\circledR}$ Alum, Pierce Biotechnology; Rockford, IL, USA). Vaccinations were completed at weeks 0,4 and 8 . Twelve animals were divided into three (3) groups, four animals per group (Table 1). For blood sample collection animals were anesthetized with a mixture of ketamine/xylazine. Sera was then harvested and stored at $-80^{\circ} \mathrm{C}$ until needed.

\section{Immune assays}

Total anti-Env ${ }_{\mathrm{gp} 160}$ IgG was detected by enzyme-linked immunosorbent assay (ELISA) using Concanavalin A $(50 \mu \mathrm{g} / \mu \mathrm{l})$ per well as previously described [8]. End point titer for assay was determined as the reciprocal of the dilution at which the optical density reading was above the mean plus two standard deviations of naïve sera. For In vitro neutralization, antisera were tested for the ability to neutralize virus infection in vitro using TZM-Bl indicator cells [8]. The sera dilution necessary to neutralize virus was calculated by the following formula (relative light units (RLU) of virus only-RLU of cell only)/ $2+$ RLU cell only. For assessment of $\mathrm{T}$ cell responses, NHP IFN- $\gamma$ ELISPOT was used to enumerate anti-Env ${ }_{\text {gp160 }}$ specific cellular responses. The number of anti-Env ${ }_{\mathrm{gp} 160}$ (SF162p3 and Con $\mathrm{M}$ ) and Gag ( $\left.\mathrm{SIV}_{\text {mac239 }}\right)$ specific IFN- $\gamma$ secreting cells were determined using the non-human primate enzyme-linked immunospot (ELISPOT) assay (R\&D Systems, Minneapolis, MN, USA).

\section{SHIV viral load determination}

Real time PCR-based SIV viral detection assay was used to determine the viral titers post-challenge as described in [48]. cDNA ( $10 \mu \mathrm{l})$ generated by the RT-RCR reaction was then used for PCR using the ABI 7000 Gene detection system (Applied Bioscience, Carlsbad, California, USA).

\section{Anti-CD8 cell depletion by antibody administration}

All animals in the Con M group were depleted of CD8+ T cells. The antibody M-T807R1 (NIH NHP Reagent Source, Beth Israel Deacones Medical Center, Boston, MA, USA) was administered subcutaneously $(50 \mathrm{mg} / \mathrm{Kg}$ ) on day 0 (Day 70 post infection). CD8+ T cell depletion was verified using TruCOUNT tubes (BD Bioscience, San Jose, CA, USA).

\section{Statistical analysis}

Statistical tests were performed using Graph Pad Prism software. Statistical significance of antibody test was determined by two-way analysis of variance (ANOVA) followed by the Bonferroni's post-hoc test. Post-test was used to analyze differences between the vaccine groups. Significance was determined to be a $\mathrm{p}<0.05$.

\section{Additional file}

Additional file 1: Figure S1. Representative sensograms of $\lg \mathrm{G} b 12$ SPR data. SPR binding isotherms detailing the interaction of each recombinant trimeric Env ${ }_{\mathrm{gp} 140}$ with the monoclonal antibody b12 are displayed. Indicated concentrations of each Env ${ }_{\mathrm{gp} 140}$ were flowed over captured b12 at $37^{\circ} \mathrm{C}$ on CM5 chips as detailed in Materials and Methods. Association rates, dissociation rates, and affinity constants were calculated with BIA evaluation 4.1.1 software (GE/Biacore AB, Uppsala, Sweden). A, ConA; B, ConB; C, ConC; D, Con M; E, ConE; F, ADA; G, PV0.04; H, R2; I, SC42; and J, YU2. Black lines are determined 1:1 Langmuir kinetic fits. RU, resonance units.

\section{Competing interests}

The authors declare that they have no competing interests.

\section{Authors' contributions}

HSE designed and performed most of the experiments analyze data and wrote the paper. BRP was instrumental in animal care and processing of animal samples. JKC performed and analyzed all Surface plasmon resonance data. She was also involve in discussion on results and implications and commented on the manuscript. Finally TMR was the supervisor on the project and was involved in discussions on the results and its implications. He was also instrumental in editing of the manuscript at all stages. All authors read and approved the final manuscript.

\section{Acknowledgements}

This research was primarily supported by an award from the National Institute of Health/National Institute of Allergy and Infectious Diseases R01Al068507 to T.M.R. The HIV and SIV specific peptides and reagents were obtained through the AIDS Research and Reference Reagent Program, Division of AIDS, NIAID, NIH including TZM-bl cells (also called JC57BL-13) (\#8129). The authors would also thank investigators that provided specific HIV-1 isolates (Rob Center, Dennis Ellenberger, Phalguni Gupta, Beatrice Hahn, David Montefiori, Gary Nabel, Yiming Shao, and Carolyn Williamson). We are also grateful to Amara Luckay and Jim Smith at the CDC for determination of viral loads. This work was supported, in part, under a grant with the Pennsylvania Department of Health. The department specifically disclaims responsibility for any analyses, interpretations or conclusions.

\section{Author details}

${ }^{1}$ Center for Vaccine Research, University of Pittsburgh, 9047 BST3; 3501 Fifth Avenue, Pittsburgh, PA 15261, USA. ²Department of Microbiology and Molecular Genetics, University of Pittsburgh, Pittsburgh, PA, USA. ${ }^{3}$ Graduate Program in Molecular Virology and Microbiology, University of Pittsburgh, Pittsburgh, PA, USA.

Received: 12 September 2012 Accepted: 28 February 2013 Published: 2 April 2013

\section{References}

1. Hemelaar J: The origin and diversity of the HIV-1 pandemic. Trends Mol Med 2012, 18(3):182-192.

2. Gaschen B, Taylor J, Yusim K, Foley B, Gao F, Lang D, Novitsky V, Haynes B, Hahn BH, Bhattacharya T, et al: Diversity Considerations in HIV-1 Vaccine Selection. Science (New York, NY) 2002, 296:2354-2360.

3. Spira S, Wainberg MA, Loemba H, Turner D, Brenner BG: Impact of clade diversity on HIV-1 virulence, antiretroviral drug sensitivity and drug resistance. J Antimicrob Chemother 2003, 51(2):229-240.

4. McBurney SP, Ross TM: Viral sequence diversity: challenges for AIDS vaccine designs. Expert Rev Vaccines 2008, 7(9):1405-1417.

5. Lu S, Grimes Serrano JM, Wang S: Polyvalent AIDS Vaccines. Curr HIV Res 2010, 8(8):622-629.

6. Arenas M, Posada D: Computational Design of Centralized HIV-1 Genes. Curr HIV Res 2010, 8(8):613-621. 
7. Gao F, Liao H-X, Hahn BH, Letvin NL, Korber BT, Haynes BF: Centralized HIV1 Envelope Immunogens and Neutralizing Antibodies. Curr HIV Res 2007, 5(6):572-577.

8. McBurney SP LG, Forthal DN, Ross TM: Evaluation of heterologous vaginal SHIV SF162p4 infection following vaccination with a polyvalent clade B virus-like particle vaccine. AIDS Res Hum Retroviruses 2012. in Press.

9. Wang S, Kennedy JS, West K, Montefiori DC, Coley S, Lawrence J, Shen S, Green S, Rothman AL, Ennis FA, et al: Cross-subtype antibody and cellular immune responses induced by a polyvalent DNA primeâ€"protein boost HIV-1 vaccine in healthy human volunteers. Vaccine 2008, 26(8):1098-1110.

10. Lakhashe SK, Wang W, Siddappa NB, Hemashettar G, Polacino P, Hu SL, Villinger F, Else JG, Novembre FJ, Yoon JK, et al: Vaccination against Heterologous R5 Clade C SHIV: Prevention of Infection and Correlates of Protection. PLoS One 2011, 6(7):e22010.

11. Yan J, Yoon H, Kumar S, Ramanathan MP, Corbitt N, Kutzler M, Dai A, Boyer JD, Weiner DB: Enhanced Cellular Immune Responses Elicited by an Engineered HIV-1 Subtype B Consensus-based Envelope DNA Vaccine. Mol Ther 2007, 15(2):411-421

12. McBurney SP, Ross TM: Human immunodeficiency virus-like particles with consensus envelopes elicited broader cell-mediated peripheral and mucosal immune responses than polyvalent and monovalent Env vaccines. Vaccine 2009, 27(32):4337-4349.

13. Santra S, Korber BT, Muldoon M, Barouch DH, Nabel GJ, Gao F, Hahn BH Haynes BF, Letvin NL: A centralized gene-based HIV-1 vaccine elicits broad cross-clade cellular immune responses in rhesus monkeys. PNAS 2008, 105(30):10489-10494.

14. Liao H-X, Sutherland LL, Xia S-M, Brock ME, Scearce RM, Vanleeuwen S, Alam SM, McAdams M, Weaver EA, Camacho ZT, et al: A group M consensus envelope glycoprotein induces antibodies that neutralize subsets of subtype B and C HIV-1 primary viruses. Virology 2006 353(2):268-282.

15. Bower JF, Li Y, Wyatt R, Ross TM: HIV-1 Envgp140 trimers elicit neutralizing antibodies without efficient induction of conformational antibodies. Vaccine 2006, 24(26):5442-5451.

16. Pantophlet R, Wilson IA, Burton DR: Improved design of an antigen with enhanced specificity for the broadly HIV-neutralizing antibody b12. PEDS 2004, 17(10):749-758.

17. Watkins JD, Siddappa NB, Lakhashe SK, Humbert M, Sholukh A, Hemashettar G, Wong YL, Yoon JK, Wang W, Novembre FJ, et al: An Anti-HIV-1 V3 Loop Antibody Fully Protects Cross-Clade and Elicits T-Cell Immunity in Macaques Mucosally Challenged with an R5 Clade C SHIV. PLoS One 2011, 6(3):e18207.

18. Barnett SW, Srivastava IK, Kan E, Zhou F, Goodsell A, Cristillo AD, Ferrai MG, Weiss DE, Letvin NL, Montefiori D, et al: Protection of macaques against vaginal SHIV challenge by systemic or mucosal and systemic vaccinations with HIV-envelope. AIDS 2008, 22(3):339-348.

19. Barnett SW, Burke B, Sun Y, Kan E, Legg H, Lian Y, Bost K, Zhou F, Goodsell A, zur Megede J, et al: Antibody-Mediated Protection against Mucosal Simian-Human Immunodeficiency Virus Challenge of Macaques Immunized with Alphavirus Replicon Particles and Boosted with Trimeric Envelope Glycoprotein in MF59 Adjuvant. J Virol 2010, 84(12):5975-5985.

20. Kothe DL, Decker JM, Li Y, Weng Z, Bibollet-Ruche F, Zammit KP, Salazar MG, Chen Y, Salazar-Gonzalez JF, Moldoveanu Z, et al: Antigenicity and immunogenicity of HIV-1 consensus subtype B envelope glycoproteins. Virology 2007, 360(1):218-234.

21. Kothe DL, Li Y, Decker JM, Bibollet-Ruche F, Zammit KP, Salazar MG, Chen Y, Weng Z, Weaver EA, Gao F, et al: Ancestral and consensus envelope immunogens for HIV-1 subtype C. Virology 2006, 352(2):438-449.

22. Barouch DH, Liu J, Li H, Maxfield LF, Abbink P, Lynch DM, lampietro MJ, SanMiguel A, Seaman MS, Ferrari G, et al: Vaccine protection against acquisition of neutralization-resistant SIV challenges in rhesus monkeys. Nature 2012. advance online publication.

23. Sharma VA, Kan E, Sun Y, Lian Y, Cisto J, Frasca V, Hilt S, Stamatatos L, Donnelly JJ, Ulmer JB, et al: Structural characteristics correlate with immune responses induced by HIV envelope glycoprotein vaccines. Virology 2006, 352(1):131-144.

24. Harris A, Borgnia MJ, Shi D, Bartesaghi A, He H, Pejchal R, Kang Y, Depetris R, Marozsan AJ, Sanders RW, et al: Trimeric HIV-1 glycoprotein gp140 immunogens and native HIV-1 envelope glycoproteins display the same closed and open quaternary molecular architectures. Proc Natl Acad Sci U S A 2011, 108:11440-11445.
25. Saphire EO, Parren PWHI, Pantophlet R, Zwick MB, Morris GM, Rudd PM, Dwek RA, Stanfield RL, Burton DR, Wilson IA: Crystal Structure of a Neutralizing Human IgG Against HIV-1: A Template for Vaccine Design. Science 2001, 293(5532):1155-1159.

26. Holl V, Peressin M, Moog C: Antibody-Mediated Fc $\psi$ Receptor-Based Mechanisms of HIV Inhibition: Recent Findings and New Vaccination Strategies. Viruses 2009, 1:1265-1294.

27. Burton DR: Antibodies, viruses and vaccines. Nat Rev Immunol 2002, 2(9):706-713.

28. Haynes BF, Gilbert PB, McElrath MJ, Zolla-Pazner S, Tomaras GD, Alam SM, Evans DT, Montefiori DC, Karnasuta C, Sutthent R, Liao HX, et al: Immunecorrelates analysis of an HIV-1 vaccine efficacy trial. N Engl J Med 2012, 366(14)):1275-86.

29. Barouch DH, Liu J, Li H, Maxfield LF, Abbink P, Lynch DM, lampietro MJ, SanMiguel A, Seaman MS, Ferrari G, et al: Vaccine protection against acquisition of neutralization-resistant SIV challenges in rhesus monkeys. Nature. advance online publication.

30. Rerks-Ngarm S, Pitisuttithum P, Nitayaphan S, Kaewkungwal J, Chiu J, Paris $R$, Premsri N, Namwat $C$, de Souza M, Adams $E$, et al: Vaccination with ALVAC and AIDSVAX to Prevent HIV-1 Infection in Thailand. N Eng J Med 2009, 361:2209-2220.

31. Haynes BF, Gilbert PB, McElrath MJ, Zolla-Pazner S, Tomaras GD, Alam SM, Evans DT, Montefiori DC, Karnasuta C, Sutthent R, et al: Immune-Correlates Analysis of an HIV-1 Vaccine Efficacy Trial. N Eng J Med 2012, 366(14):1275-1286.

32. Hessell AJ, Rakasz EG, Tehrani DM, Huber M, Weisgrau KL, Landucci G, Forthal DN, Koff WC, Poignard P, Watkins DI, et al: Broadly Neutralizing Monoclonal Antibodies 2F5 and 4E10 Directed against the Human Immunodeficiency Virus Type 1 gp41 Membrane-Proximal External Region Protect against Mucosal Challenge by Simian-Human Immunodeficiency Virus SHIVBa-L. J Virol 2009, 84:1302-1313.

33. Barnett SW, Srivastava IK, Kan E, Zhou F, Goodsell A, Cristillo AD, Ferrai MG, Weiss DE, Letvin NL, Montefiori D, et al: Protection of macaques against vaginal SHIV challenge by systemic or mucosal and systemic vaccinations with HIV-envelope. AIDS 2008, 22(3):339-348.

34. Smith M, Wightman F, Lewin S: HIV Reservoirs and strategies for eradication. Curr HIV/AIDS Rep 2012, 9:5-15.

35. Veazey RS, Acierno PM, McEvers KJ, Baumeister SHC, Foster GJ, Rett MD, Newberg MH, Kuroda MJ, Williams K, Kim E-Y, et al: Increased Loss of CCR5+

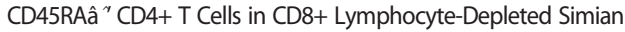
Immunodeficiency Virus-Infected Rhesus Monkeys. J Virol 2008, 82:5618-5630.

36. Loffredo JT, Maxwell J, Qi Y, Glidden CE, Borchardt GJ, Soma T, Bean AT, Beal DR, Wilson NA, Rehrauer WM, et al: Mamu-B*08-Positive Macaques Control Simian Immunodeficiency Virus Replication. J Virol 2007, 81:8827-8832.

37. Lakhashe SK, Velu V, Siddappa NB, Dipasquale JM, Hemashettar G, Yoon JK, Rasmussen RA, Yang F, Lee SJ, Montefiori DC, et al: Prime-boost vaccination with heterologous live vectors encoding SIV gag and multimeric HIV-1 gp160 protein: efficacy against repeated mucosal R5 clade C SHIV challenges. Vaccine 2011, 29(34):5611-24.

38. Sundling C, Forsell MN, O'Dell S, Feng Y, Chakrabarti B, Rao SS, Loré K, Mascola JR, Wyatt RT, Douagi I, et al: Soluble HIV-1 Env trimers in adjuvant elicit potent and diverse functional $B$ cell responses in primates. J Exp Med 2010, 207(9):2003-2017.

39. Leroux-Roels I, Koutsoukos M, Clement F, Steyaert S, Janssens M, Bourguignon $\mathrm{P}$, Cohen $\mathrm{K}$, Altfeld $\mathrm{M}$, Vandepapelière $\mathrm{P}$, Pedneault $\mathrm{L}$, et al: Strong and persistent CD4+ T-cell response in healthy adults immunized with a candidate HIV-1 vaccine containing gp120, Nef and Tat antigens formulated in three Adjuvant Systems. Vaccine 2010, 28(43):7016-7024.

40. Gavioli R, Cellini S, Castaldello A, Voltan R, Gallerani E, Gagliardoni F, Fortini C, Cofano EB, Triulzi C, Cafaro A, et al: The Tat protein broadens T cell responses directed to the HIV-1 antigens Gag and Env: Implications for the design of new vaccination strategies against AIDS. Vaccine 2008, 26(5):727-737.

41. Ferrantelli F, Maggiorella MT, Schiavoni I, Sernicola L, Olivieri E, Farcomeni S, Pavone-Cossut MR, Moretti S, Belli R, Collacchi B, et al: A combination HIV vaccine based on Tat and Env proteins was immunogenic and protected macaques from mucosal SHIV challenge in a pilot study. Vaccine 2011 29(16):2918-2932

42. Ferre AL, Lemongello D, Hunt PW, Morris MM, Garcia JC, Pollard RB, Yee HF, Martin JN, Deeks SG, Shacklett BL: Immunodominant HIV-Specific CD8+ TCell Responses Are Common to Blood and Gastrointestinal Mucosa, and Gag-Specific Responses Dominate in Rectal Mucosa of HIV Controllers. J Virol 2010, 84(19):10354-10365. 
43. Ranasinghe S, Flanders M, Cutler S, Soghoian DZ, Ghebremichael M, Davis I, Lindqvist M, Pereyra F, Walker BD, Heckerman D, et al: HIV-Specific CD4 T Cell Responses to Different Viral Proteins Have Discordant Associations with Viral Load and Clinical Outcome. J Virol 2011, 86(1):277-283.

44. Toapanta FR, DeAlmeida DR, Dunn MD, Ross TM: C3d adjuvant activity is reduced by altering residues involved in the electronegative binding of C3d to CR2. Immunol Lett 2010, 129(1):32-38.

45. Bower JF, Ross TM: A Minimum CR2 Binding Domain of C3d Enhances Immunity Following Vaccination. In Current Topics in Complement vol. 586. Edited by Lambris JD. US: Springer; 2006:249-264.

46. Young KR, Smith JM, Ross TM: Characterization of a DNA vaccine expressing a human immunodeficiency virus-like particle. Virology 2004, 327(2):262-272.

47. Steckbeck JD, Orlov I, Chow A, Grieser H, Miller K, Bruno J, Robinson JE, Montelaro RC, Cole KS: Kinetic Rates of Antibody Binding Correlate with Neutralization Sensitivity of Variant Simian Immunodeficiency Virus Strains. J Virol 2005, 79(19):12311-12320.

48. Subbarao S, Otten RA, Ramos A, Kim C, Jackson E, Monsour M, Adams DR, Bashirian S, Johnson J, Soriano V, et al: Chemoprophylaxis with Tenofovir Disoproxil Fumarate provided partial protection against infection with simian human immunodeficiency virus in macaques given multiple virus challenges. J Infect Dis 2006, 194(7):904-911.

doi:10.1186/1743-422X-10-102

Cite this article as: Eugene et al:: Rhesus macaques vaccinated with consensus envelopes elicit partially protective immune responses against SHIV SF162p4 challenge. Virology Journal 2013 10:102.

\section{Submit your next manuscript to BioMed Central and take full advantage of:}

- Convenient online submission

- Thorough peer review

- No space constraints or color figure charges

- Immediate publication on acceptance

- Inclusion in PubMed, CAS, Scopus and Google Scholar

- Research which is freely available for redistribution 